\title{
Gestão de custos ambientais: implementação do selo verde em postos de combustíveis
}

A presente pesquisa teve como objetivo identificar as variações nos custos dos postos de combustíveis após a implementação do projeto do selo verde, proposto pelo Ministério Público do Rio Grande do Norte (MP/RN). Para contemplar esta finalidade, verificou-se as informações sobre investimentos realizados, para a adequação e obtenção da certificação, além da depreciação dos mesmos. Esta pesquisa configura-se como descritiva por observar, registrar, analisar e ordenar os fatos, sem manipulá-los, isto é, sem interferir neles. A investigação de campo transcorreu entre janeiro e março de 2016, nos postos de combustíveis da capital do Rio Grande do Norte, sendo a população formada pelo diretor ou gerente geral das empresas. Quanto à abordagem do problema, o percurso de pesquisa utilizado foi o método qualitativo, pelo fato de se tratar de uma sequência de atividades de investigação, a qual envolve a redução dos dados, a sua categoria, sua interpretação e a redação do relatório de acordo com o objeto de pesquisa da análise. Verificou-se que, apesar do valor em aquisições, ao qual variou entre $\mathrm{R} \$ 200.000,00$ e $\mathrm{R} \$ 1.000 .000,00$, ser muito alto e do baixo retorno alcançado até a conclusão desta pesquisa, os respondentes acreditam que a médio e longo prazo haverá uma resposta positiva à certificação, uma vez que em suas interpretações e visões de oportunidade, o selo verde além de agregar valor mercadológico aos postos de combustíveis inseridos no processo, os estabelecimentos estarão preparados para enfrentar desafios futuros nos aspectos econômicos, sociais e ambientais

Palavras-chave: Gestão Ambiental; Contabilidade Ambiental; Sustentabilidade; Responsabilidade Coorporativa; Visão de Futuro.

\section{Environmental cost management: implementation of green seal at gas stations}

\begin{abstract}
This research aimed to identify the variations in gas station costs after the implementation of the green seal project, proposed by the Public Prosecutor of Rio Grande do Norte (MP / RN). To meet this purpose, information on investments made was verified, for the adequacy and obtaining of certification, as well as their depreciation. This research is configured as descriptive for observing, recording, analyzing and ordering the facts, without manipulating them, that is, without interfering with them. The field investigation took place between January and March 2016, at the gas stations of the capital of Rio Grande do Norte, with the population formed by the director or general manager of the companies. Regarding the approach to the problem, the research pathway used was the qualitative method, because it is a sequence of research activities, which involves the reduction of data, its category, its interpretation and the writing of the report accordingly. with the research object of the analysis. Although the value in acquisitions, which ranged from $R \$ 200.000,00$ to $R \$ 1.000 .000,00$, was found to be very high and the low return achieved until the completion of this survey, respondents believe that in the medium and long term There will be a positive response to certification, since in their interpretations and views of opportunity, the green seal in addition to adding market value to the gas stations inserted in the process, the establishments will be prepared to face future economic, social and environmental challenges.
\end{abstract}

Keywords: Environmental management; Environmental accounting; Sustainability; Corporate Responsibility; Future vision.

Topic: Contabilidade Ambiental

Reviewed anonymously in the process of blind peer.
Received: $\mathbf{2 4 / 0 8 / 2 0 1 8}$

Approved: 29/08/2018
Glauce Vitor da Silva

Universidade Federal do Oeste do Pará, Brasil

http://lattes.cnpq.br/0491000360565155

glaucevitor@yahoo.com.br

Georgiana Adalgiza Morais Mendes

Universidade do Estado do Rio Grande do Norte, Brasil

http://lattes.cnpq.br/9082743478055574

georgianamendes2010@hotmail.com

Larissa Bezerra Calado

Universidade do Estado do Rio Grande do Norte, Brasil http://lattes.cnpq.br/9707566194674001

larissacal2011@hotmail.com
Francisco Igo Leite Soares

Universidade Federal do Oeste do Pará, Brasil http://lattes.cnpq.br/5938594695650101

francisco.soares@ufopa.edu.br

Auris Martins de Oliveira (iD

Universidade do Estado do Rio Grande do Norte, Brasil http://lattes.cnpq.br/7836260894118472 http://orcid.org/0000-0002-7034-7654 auris martins@hotmail.com

Léo César Parente de Almeida

Universidade Federal do Oeste do Pará, Brasil http://lattes.cnpq.br/4081029452825767 leocesarparente@gmail.com
Marco Aurélio Oliveira Santos Universidade Federal do Oeste do Pará, Brasil http://lattes.cnpq.br/5333754444497512

http://orcid.org/0000-0003-3039-6264 marcooliveira santos@yahoo.com.br

Rosângela Queiroz Souza Valdevino ic Universidade Federal do Oeste do Pará, Brasil http://lattes.cnpq.br/3215382790717735 http://orcid.org/0000-0001-7606-3006 rosangelaqueiroz84@yahoo.com.br

\section{Referencing this:}

SILVA, G. V.; MENDES, G. A. M.; CALADO, L. B.; SOARES, F. I. L.; OLIVEIRA, A. M.; ALMEIDA, L. C. P.; SANTOS, M. A. O.; VALDEVINO, R. Q. S.. Gestão de custos ambientais: implementação do selo verde em postos de combustíveis. Revista Ibero-Americana de Ciências Ambientais, v.9, n.6, p.383-390, 2018. DOI:

http://doi.org/10.6008/CBPC2179-6858.2018.006.0035 


\section{INTRODUÇÃO}

Com o incremento da competitividade cada vez mais em alta na economia, a sociedade tem estado mais preocupada com os impactos que vem causando ao meio ambiente, demandando das empresas uma postura social e ambientalmente sustentável (BORTOLUZZI et al., 2016). Assim, o crescimento econômico e as constantes cobranças das organizações têm levado as empresas a discorrerem mais sobre a responsabilidade ecológica, incluindo a proteção ambiental como objetivo dos seus negócios (SANTOS et al., 2010).

Tão importante quanto o planejamento econômico de uma empresa, é a sustentabilidade, no mais amplo conceito de desenvolvimento sustentável, no qual os objetivos de crescimento estão integrados aos esforços de redução dos impactos negativos causados ao meio ambiente (STROBEL et al., 2004). Por meio de contabilidade da gestão ambiental, é possível o estudo do patrimônio ambiental (bens, direitos e obrigações ambientais) das organizações, de forma a acumular, mensurar, analisar e divulgar informações sobre as eventuais atividades cometidas junto ao meio ambiente (TINOCO et al., 2006).

De acordo com Martins et al. (1994) as notas registradas pela contabilidade, vão desde a "aquisição de bens permanentes de proteção a danos ecológicos, de despesas de manutenção ou correção de efeitos ambientais do exercício em curso, de obrigações contraídas em prol do meio ambiente, e até de medidas físicas, quantitativas e qualitativas, empreendidas para sua recuperação e preservação".

Ao realizar o gerenciamento ambiental, a ciência contábil interage com a administração, em função da eficácia do processo (SANTOS et al., 2001). Segundo Paula (2015) a responsabilidade social e a sustentabilidade, compõem o cenário empresarial e representam uma oportunidade de vantagem competitiva.

Desta forma, a contabilidade ambiental pode ser considerada, uma ferramenta de gestão dos negócios, pois auxilia os administradores no planejamento empresarial do meio ambiente, informando em seus relatórios todos os dados que envolvam os recursos naturais (TINOCO et al., 2006). A própria gestão ambiental visa ordenar as atividades humanas, para que estas originem o menor impacto possível sobre o meio. Isso vai desde o início da atividade, na escolha da melhor técnica, até o cumprimento da legislação e a colocação correta de recursos.

Em meio ao processo de busca pelo crescimento e/ou desenvolvimento econômico encontra-se a indústria química, uma das principais atividades que impulsiona diversos setores da economia no mundo, tais como a comercialização petroquímica (GIARDINI et al., 2017). Nesta pesquisa, destaca-se a importância da implementação do selo verde em postos revendedores de combustíveis em Natal (RN). O selo verde ou certificação representa uma excelente estratégia competitiva, importante para o marketing da empresa, a qual atende à legislação em vigência, satisfazendo a qualidade mínima ou critérios de excelência (BORTOLUZZI et al., 2016).

A partir da Lei Federal no 6.938/81, regulamentada pelo Decreto Federal no 99.274/90, a atividade de comércio desenvolvida por postos de combustíveis está submetida à legislação ambiental, sujeita ao licenciamento ambiental pela Resolução do Conselho Nacional do Meio Ambiente - CONAMA no 237/97, 
seguida pela resolução CONAMA no 273/2000, que trata, especificamente, da padronização e licenciamento das atividades que possuem reservatórios e armazenamento de combustíveis, constituindo a mais abrangente e mais importante legislação referente à tratativa.

Neste sentido, tem-se como objetivo identificar as variações nos custos dos postos de combustíveis após a certificação emitida pelo Ministério Público do Rio Grande do Norte (MP/RN), a partir de 2009, por meio do Projeto Selo Verde, na tentativa de evitar irregularidades relativas ao licenciamento ambiental, ao controle e ao funcionamento de postos de comercialização de combustíveis na capital Potiguar.

\section{METODOLOGIA}

A pesquisa apresenta caráter exploratório, de natureza básica, que segundo Cervo et al. (2005) tratase da busca pelo saber para satisfazer uma necessidade intelectual pelo conhecimento. Os métodos desenvolvidos para esta pesquisa obedeceram a uma ordenação baseada em informações bibliográficas - em todas as suas etapas - e em trabalho de campo. Para esta pesquisa, foi feita uma amostragem intencional não-probabilística, ou seja, foram apontadas pelo pesquisador, ao qual, de acordo com Fávero (2009), pode ser aplicado quando a participação é voluntária ou os elementos da amostra são escolhidos por uma questão de conveniência ou simplicidade.

A investigação de campo transcorreu-se nos meses de janeiro a março de 2016, em quatro postos de combustíveis situados no município de Natal (RN), sendo direcionada ao diretor ou gerente geral de cada empresa. Para a pesquisa, averiguou-se a literatura específica, por meio de textos com validade científica, objetivando sistematizar o referencial teórico que fundamentam esta abordagem (PRODANOV et al., 2013). Para captação dos dados, foi feito um questionário, enviado por e-mail em um link. O questionário é composto por 12 questões, contendo perguntas: dicotômicas envolvendo 'sim ou não'; aberta opcional, complementar; e de grau de concordância; há também identificação - confidencial - do entrevistado, por nome, cargo na empresa, nome da empresa e contato de e-mail (MARCONI et al., 2003).

No que se refere ao conteúdo das perguntas, foram enfocados os impactos causados nos custos para a certificação do selo verde e quais impactos à depreciação dos investimentos em ativos, exerceu nos valores dos custos dos postos de combustíveis causados por esse investimento. Logo, nos aspectos contábeis foram abordados questionamentos sobre o uso ou não das demonstrações contábeis, para divulgar a interação existente entre suas atividades operacionais e o meio ambiente natural, e se no balanço patrimonial, portanto, os gastos ambientais seriam segregados dos demais gastos, além da depreciação dos ativos. Quanto ao tratamento dos dados, o método utilizado para apuração dos resultados foi a análise de conteúdo, que segundo Bardin (2009), é um conjunto de técnicas de análise das comunicações que utiliza procedimentos sistemáticos e objetivos de descrição do conteúdo das mensagens.

Uma análise estrutural da percepção das informações adquiridas será apresentada na forma da matriz no modelo DPSIR: Forças Motoras (Driving Forces) refletem as influências das atividades humanas que, quando combinadas com as condições ambientais, provocam mudança no meio ambiente; as Pressões (Pressures) descrevem as variáveis que diretamente causam problemas ambientais; essas pressões afetam o 
Estado (State), atual condição do ambiente; Impacto (Impact) expõe os efeitos das mudanças de estado e as respostas (Responses) delineiam o esforço para resolver os problemas, na forma de políticas, leis, tecnologias limpas, dentre outras (FERNANDES et al., 2011).

\section{RESULTADOS E DISCUSSÃO}

$\mathrm{Na}$ análise dos resultados, foi perceptível que o Posto de combustível A foi o único que já atendia a quase todas as normas exigidas para certificação do selo verde, e os seguintes Posto B, Posto C e Posto D, afirmaram que atendiam parcialmente, mas mesmo assim tiveram que assinar o termo de ajustamento de conduta para atingir 100\% das exigências. Em sequência foi questionado o que foi feito inicialmente para o procedimento de aquisição do Selo Verde. O posto $\mathrm{A}$ afirmou o pagamento de empresas especializadas em perícias; posto B, C e D fizeram investimentos para adequações às normas legais. Posteriormente buscou-se averiguar quais mudanças foram necessárias na estrutura do posto e quais aquisições de equipamentos foram feitas (quadro 1).

Quadro 1: Investimentos realizados pelas empresas.

\begin{tabular}{|c|l|}
\hline EMPRESA & \multicolumn{1}{c|}{ AQUISçõES } \\
\hline Posto A & Compra de tanques ecológicos e aquisição de bombas eletrônicas de abastecimento. \\
\hline Posto B & $\begin{array}{l}\text { Investiu-se em tanques ecológicos; implantação de caneletas colocadas ao redor do perímetro do posto, nas áreas } \\
\text { de risco, para condução dos fluidos líquidos até a caixa separadora; compra de bombas eletrônicas de abastecimento; } \\
\text { instalação da unidade coletora de água da chuva, e de um reservatório para estocagem dessa água; construção de } \\
\text { uma caixa separadora de água e óleo; construção dos poços de monitoramento; e impermeabilização do piso. }\end{array}$ \\
\hline Posto C & $\begin{array}{l}\text { Obtenção de tanques ecológicos; implantação de caneletas colocadas ao redor do perímetro do posto, nas áreas de } \\
\text { risco, para condução dos fluidos líquidos até a caixa separadora; aquisição de bombas eletrônicas de abastecimento; } \\
\text { construção da unidade coletora de água da chuva, e de um reservatório para estocagem dessa água; construção de } \\
\text { uma caixa separadora de água e óleo; construção dos poços de monitoramento, e impermeabilização do piso, além } \\
\text { de reforma na loja }\end{array}$ \\
\hline Posto D & $\begin{array}{l}\text { Adquiriram-se tanques ecológicos; implantação de caneletas colocadas ao redor do perímetro do posto, nas áreas } \\
\text { de risco, para condução dos fluidos líquidos até a caixa separadora; aquisição de bombas eletrônicas de } \\
\text { abastecimento; construção da unidade coletora de água da chuva, e de um reservatório para estocagem dessa água; } \\
\text { construção de uma caixa separadora de água e óleo; construção dos poços de monitoramento; e impermeabilização } \\
\text { do piso. }\end{array}$ \\
\hline
\end{tabular}

A resolução do CONAMA 273/2000, a qual trata, especificamente, da padronização e licenciamento das atividades que possuem reservatórios e armazenamento de combustíveis, estabelece que para emissão de licenças ambientais deve-se ficar claro que os postos de combustíveis contenham os equipamentos e sistemas de monitoramento, proteção, sistema de detecção de monitoramento, sistema de drenagem e tanques de armazenamento de derivados de petróleo.

Santos (2005) afirma que os estabelecimentos que revendem combustíveis possuem, basicamente: a unidade de abastecimento de veículos, os tanques de combustíveis - geralmente enterrados -, os pontos de descarga de combustíveis, o tanque para recolhimento e guarda de óleo lubrificante usado - geralmente enterrados -, a unidade de filtragem de diesel, o sistema de drenagens oleosas e fluviais e os equipamentos de proteção e controle de derrames e vazamentos de combustíveis. Mas para adequar-se ao Projeto Selo Verde, a resolução do CONAMA 273/2000 estabelece alguns documentos específicos para emissão de licenças ambientais, conforme se visualiza na tabela 1. 
Tabela 1: Documentos específicos para a emissão de licenças ambientais.

\begin{tabular}{|c|c|}
\hline Licença previa e licença de instalação & Licença de operação \\
\hline $\begin{array}{l}\text { A) Projeto básico, que deverá especificar os equipamentos e } \\
\text { sistemas de monitoramento, proteção, sistema de detecção } \\
\text { de monitoramento, sistema de drenagem e tanques de } \\
\text { armazenamento de derivados de petróleo. } \\
\text { B) Declaração da prefeitura municipal de que o local e o tipo } \\
\text { de empreendimento / atividade estão em conformidade } \\
\text { com o plano diretor; } \\
\text { C) Croqui de localização do empreendimento. D) } \\
\text { Caracterização hidrogeológica, no raio de } 100 \text { metros do } \\
\text { estabelecimento comercial. } \\
\text { E) Caracterização geológica, no raio de } 100 \text { metros do } \\
\text { estabelecimento comercial. } \\
\text { F) Classificação da área do entorno dos estabelecimentos } \\
\text { que utilizam o sistema de armazenamento subterrâneo de } \\
\text { combustível - SASC e enquadramento deste sistema, } \\
\text { conforme NBR-13.786. } \\
\text { G) Detalhamento do tipo de controle de efluentes } \\
\text { provenientes dos tanques, áreas de bomba e áreas sujeitas } \\
\text { a vazamentos. } \\
\text { H) Previsão no projeto de dispositivos com necessidade de } \\
\text { recolhimento e disposição adequada de óleo lubrificante } \\
\text { usado. }\end{array}$ & $\begin{array}{l}\text { A) Plano de manutenção de equipamentos/sistemas e } \\
\text { procedimentos operacionais. } \\
\text { B) Plano de respostas a incidentes. } \\
\text { C) Atestado de vistoria do corpo de bombeiros. } \\
\text { D) Programa de treinamento de pessoal. E) Registro do pedido de } \\
\text { autorização para funcionamento na Agência Nacional de Petróleo } \\
\text { (ANP). } \\
\text { F) Certificados expedidos pelo Instituto Nacional de Metrologia, } \\
\text { Normatização e Qualidade Instrumental (INMETRO), atestando a } \\
\text { conformidade quanto à fabricação, montagem e comissiona- } \\
\text { mento dos equipamentos e sistemas. } \\
\text { G) Certificado expedido pelo INMETRO, atestando a inexistência } \\
\text { de vazamentos. }\end{array}$ \\
\hline
\end{tabular}

Diante do exposto, os postos de combustíveis de Natal (RN), investigados nesta pesquisa, precisaram ajustar suas condutas e investir em infraestrutura e equipamentos, como se pode observar no quadro 2 , aos quais agregassem qualidade, segurança e melhor desempenho de suas atividades. 0 quadro 2 foi intitulado 'As quatro etapas que constituem o Projeto Selo Verde'.

Quadro 2: As quatro etapas que constituem o Projeto Selo Verde.

\begin{tabular}{|c|l|}
\hline $\begin{array}{c}\text { Levantamento } \\
\text { Inicial }\end{array}$ & $\begin{array}{l}\text { Levantamento das atividades dos postos de combustível; Levantamento das normas ambientais vigentes; Levantamento } \\
\text { dos postos atuantes na cidade; Volume de tanques e capacidade de armazena mento de combustível nos tanques da } \\
\text { cidade, além da idade destes tanques; Levantamento dos postos atuantes sem a licença de operação (LO) ou com tal } \\
\text { licença vencida; Levantamento das condições de concessão das LO para os postos de combustível que detinham tal } \\
\text { licença. }\end{array}$ \\
\hline $\begin{array}{c}\text { Desenvolvimento } \\
\text { do Projeto }\end{array}$ & $\begin{array}{l}\text { Cadastramento das empresas prestadoras de serviços; Análise de todos os pedidos de licenciamento ambiental relativos } \\
\text { à atividade; Vistoria realizada pelos peritos, conhecida como "revisão de Segurança". }\end{array}$ \\
\hline $\begin{array}{c}\text { Proposta de } \\
\text { adequação }\end{array}$ & $\begin{array}{l}\text { Documento detalhado, contendo todas as obrigações dos postos de abastecimento de combustíveis, prazo para } \\
\text { conformação da exigência legal e reparação dos danos que, por ventura, existissem. }\end{array}$ \\
\hline Selo Verde & $\begin{array}{l}\text { A realização de todas as reformas necessárias para adequação ambiental, o cumprimento de todas as medidas do termo } \\
\text { de ajustamento de conduta, ao qual não teve passivo para recuperar (ou recuperou a área contaminada) e que conseguiu } \\
\text { sua licença de operação (LO), garante o recebimento de um Selo Verde, emitido pelo Ministério Público do Rio Grande do } \\
\text { Norte. }\end{array}$ \\
\hline
\end{tabular}

Fonte: Meneses et al. (2005).

Nesta perspectiva de adequações, foi questionado aos gestores qual o valor médio dos investimentos feitos para atender as exigências do selo verde. O posto $A$ informou que houve um investimento de cerca de $R \$ 200.000,00$; já os postos $B, C$ e D investiram, aproximadamente, $R \$ 1.000 .000,00$. Essa diferença entre o primeiro e os demais postos citados justifica-se pela quantidade de alterações adquiridas (quadro 1). De acordo com Rover et al. (2008), os investimentos ambientais, compreendem as ações adotadas para a gestão ambientalmente responsável. Para a BOVESPA (2018), os "investimentos Socialmente Responsáveis - SRI" agregam valor mercadológico às empresas e as deixam mais preparadas para enfrentar riscos econômicos, sociais e ambientais. No entanto, o investimento, por si só, não é suficiente, para garantir o desempenho ambiental da empresa, faz-se necessário controlar a execução e resultado das aquisições (RIBEIRO, 1998). 
Nesse sentido, questionou-se se houve impacto econômico quanto aos investimentos em relação ao custo do combustível e ao seu valor de venda. Os postos $A, B$ e $C$ descreveram que não ocorreu impacto nos valores da depreciação, diferentemente do posto D que respondeu sim, absorveram os custos. De acordo com Kaplan et al. (1998), o custo absorvido considera o investimento realizado pela empresa, no momento da venda, indicando uma relação entre receita e despesa, na apuração do resultado; logo, o gasto em infraestrutura e equipamentos realizados pelo posto $D$, para adequação e conquista do Selo Verde, foram acrescidos ao valor dos serviços prestados e da revenda de combustíveis. Desse modo, a alteração na precificação garante que o consumidor arque com o investimento.

Quanto ao prejuízo na atribuição de receitas, no período de adequação do posto, os postos $B, C$ e D, descreveram que sim, houve prejuízo na atribuição de receitas. Contudo, o posto $A$ informou não ter ocorrido prejuízo na atribuição de receitas. A empresa que apresentou o menor valor referente às aquisições para adequação, além de não contabilizar depreciação, não indicou perdas nas baixas, ou seja, não expôs sacrifício financeiro no caixa, em relação ao ativo em questão.

Ao serem questionados sobre as vendas durante o período de adequação ao selo verde, verificou-se que houve uma flutuação na comercialização de combustíveis. O posto A apresentou maior crescimento, cerca de $10 \%$, seguido dos Postos B e C, com cerca de 6\%; já o posto $D$ apresentou o crescimento mais discreto - acredita-se que tal fato se deve ao maior reajuste no preço de revenda -. Uma vez que a concepção do preço de venda de bens e serviços nas empresas estabelece-se em uma estratégia competitiva de grande relevância para as organizações (SANTOS 1997).

Sobre o retorno em relação ao investimento, todos os postos informaram que até momento da pesquisa de campo não houve, portanto, não se registrou, a partir das aquisições, um lucro contábil, ao qual refere-se à mensuração por confrontação entre receitas e despesas, quando a venda é realizada (CHANG, 1962). No entanto, o aumento no número de vendas apresentou um cenário otimista ao empresariado, ao qual afirma que vale a pena adequar-se ao Projeto Selo Verde.

De acordo coma a BOVESPA (2018), considera-se que os investimentos realizados em empresas com políticas mis sustentáveis suscitam valor para os proprietários a longo prazo; no entanto, suas organizações estarão mais preparadas para enfrentar riscos econômicos, sociais e ambientais. Em uma análise estrutural da pesquisa de campo, verificou-se que a partir do proposto pelo Ministério Público do Rio Grande do Norte, os postos de combustíveis, os quais não se adequavam as normas ambientais, chega-se as possíveis respostas que objetivam minimizar os impactos causados pela atividade (quadro 3 ).

Quadro 03: Análise pelo modelo DPSIR da variável: gestão ambiental a partir do processo de adequação ao Projeto Selo Verde.

\begin{tabular}{|c|l|}
\hline Variável & Gestão Ambiental. \\
\hline $\begin{array}{c}\text { Forças Motoras } \\
\text { (Driving Forces) }\end{array}$ & Termo de conduta proposto pelo Ministério Público do estado do Rio Grande do Norte, Projeto Selo Verde. \\
\hline Pressões (Pressures) & $\begin{array}{l}\text { Irregularidades relativas ao licenciamento ambiental, ao controle e ao funcionamento de postos de comercialização de } \\
\text { combustíveis na cidade de Natal (RN). }\end{array}$ \\
\hline Estado (State) & $\begin{array}{l}\text { Danos causados direta ou indiretamente ao meio ambiente, relativos à instalação, operação, manutenção e desativação } \\
\text { de elementos e máquinas pertencentes ao sistema de armazenamento subterrâneo de combustíveis. }\end{array}$ \\
\hline Impactos (Impacts) & Poluição e Contaminação Ambiental. \\
\hline Respostas (Responses) & Investimentos em infraestrutura e equipamentos, para obtenção do selo verde. \\
\hline
\end{tabular}




\section{CONCLUSÕES}

Inicialmente, houve resistência por parte dos informantes, ao ceder algumas informações; no entanto, fora exposto a importância da divulgação dos relatos sobre a experiência de adequação à certificação ambiental. Foram identificadas variações nos custos dos postos de combustíveis após a implementação do Projeto do selo verde, proposto pelo Ministério Público do Rio Grande do Norte (MP/RN).

Também foram diagnosticados que os custos operacionais dos estabelecimentos antes e após a adesão a recomendação do $\mathrm{MP} / \mathrm{RN}$ causaram impactos significativos, em virtude do aumento na depreciação e de outras ações acerca da adequação as normas ambientais. Entretanto, uma das empresas pesquisadas afirmou que não repassou esse ônus financeiro para o consumidor final. Inicialmente, verificou-se que as empresas pesquisadas não atendiam às normas de adequações ambientais e precisaram investir em equipamentos e métodos, com o intuito de minimizar os impactos causados pela atividade, além de realizar ajustes para padronização e licenciamento das atividades que possuem reservatórios e armazenamento de combustíveis.

Apesar do alto valor em aquisições, ao qual variou entre $R \$ 200.000,00$ e $R \$ 1.000 .000,00$, e do baixo retorno alcançado até a conclusão dessa pesquisa, os respondentes acreditam que a médio e longo prazo haverá uma resposta positiva à certificação, uma vez que em suas interpretações e visões de oportunidade o selo verde além de agregar valor mercadológico aos postos de combustíveis inseridos no processo, os estabelecimentos estarão preparados para enfrentar desafios futuros nos aspectos econômicos, sociais e ambientais.

\section{REFERÊNCIAS}

BARDIN, L.. Análise de Conteúdo. Lisboa: Edições 70, 2009.

BORTOLUZZI, F.; BONEMBERGER, S. Z.; BERTOLINI, G. R. F.; JOHANN, J. A.. Certificação ambiental: a percepção e perfil dos clientes de uma oficina de refrigeração automotiva. Revista Ibero-Americana de Ciências Ambientais, Aquidabã, v.7, n.2, p.174-187, 2016.

BOVESPA. Bolsa de valores de São Paulo. Informações, índice ISE. São Paulo: BOVESPA, 2018.

BRASIL. Resolução do CONAMA 273 de 29 de novembro de 2000. Brasília: CONAMA, 2000.

CERVO, A. L.; BERVIAN, P. A.. Metodologia Científica. 5 ed. São Paulo: Pearson Prentice Hall, 2005.

CHANG, E. C.. Business income in accounting and economics. The Accounting Review, p.248-251, 1962.

FÁVERO, L. P.; BELFIORE, P.; SILVA, F. L.; CHAN, B. L.. Análise de dados: Modelagem multivariada para tomada de decisões. Rio de Janeiro: Elsevier, 2009

FERNANDES, M. F.; BARBOSA, M. P.. Aplicações dos Indicadores Socioeconômicos e Ambientais no Modelo DPSIR (Força Motriz/Pressão/Estado/Impacto/Resposta) e Influências na Desertificação nos Municípios de Araripina-PI,
Crato e Barbalha-CE e Marcolândia-PI. Revista Brasileira de Geografia Física, v.4, p.722-737, 2011.

GIARDINI, I.; POÇA, K. S.; SILVA, V. S. P.; MELLO, M. S. C.; FRIEDRICH, K.. Vigilância sanitária em postos de revenda de combustíveis: aplicação de um modelo para integrar ações e promover a saúde do trabalhador. Revista Brasileira de Saúde Ocupacional, v.42, 2017.

KAPLAN, R. S.; COOPER, R.. Custo \& desempenho: administre seus custos para ser mais competitivo. São Paulo: Futura, 1998.

MARCONI, M. A.; LAKATOS, E. M.. Fundamentos de metodologia científica. 5 ed. São Paulo: Atlas, 2003.

MARTINS, E.; LUCA, M. M. M.. Ecologia via Contabilidade. Revista Brasileira de Contabilidade, Brasília, v.23, n.86, 1994.

MENESES, C. G. R.; FLOR, R. V.. Avaliação da implantação do selo verde: estudo de caso em um posto de revenda de combustível na cidade do Natal/RN. Revista Eletrônica do Mestrado Profissional em Engenharia de Petróleo e Gás da Universidade Potiguar, v.2, n.1, 2014.

PAULA, H. C.. Responsabilidade social de um grande banco de varejo brasileiro. Revista Ibero-Americana de Ciências Ambientais, Aquidabã, v.6, n.2, p.144-158, 2015. 
PRODANOV, C. C.; FREITAS, E. C.. Metodologia do trabalho científico: métodos e técnicas da pesquisa e do trabalho acadêmico. Porto Alegre: 2013.

RIBEIRO, M. S.. O custeio por atividades aplicado ao tratamento contábil dos gastos de natureza ambiental. Cadernos de Estudos, São Paulo, n.19, 1998.

ROVER, S.; BORBA, J. A.; BORGERT, A.. Como as empresas classificadas no índice de sustentabilidade empresarial (ISE) evidenciam os custos e investimentos ambientais. Custos e Agronegócio Online, v.4, n.1, p.1-25, 2008.

SANTOS, A. O.; SILVA, F. B.; SOUZA, S.; SOUSA, M. F. R. Contabilidade Ambiental: um estudo sobre sua aplicabilidade em Empresas Brasileiras. Revista Contabilidade \& Finanças, São Paulo, FIPECAFI, v.16, n. 27 , p.89-99, 2001.
SANTOS, R. F.; RODRIGUES, M. G.. Dilemas do crescimento econômico sustentável. Revista Ibero-Americana de Ciências Ambientais, Aquidabã, v.1, n.1, p.5-15, 2010.

SANTOS, R. J.. A gestão ambiental em posto revendedor de combustíveis como instrumento de prevenção de passivos ambientais. Dissertação (Mestrado em Sistemas de Gestão do Meio Ambiente) - Universidade Federal Fluminense, Niterói, 2005.

SANTOS, R. V.. Planejamento do preço de venda. Caderno de Estudos, São Paulo, v.9, n.15, p.60-74, 1997.

STROBEL, J. S.; CORAL, E.; SELIG, P. M.. Indicadores de sustentabilidade corporativa: uma análise comparativa. In: ENCONTRO ANUAL DA ANPAD, 28. Anais. Curitiba: 2004.

TINOCO, J. E. P.; ROBLES, L. T.. A contabilidade da gestão ambiental e sua dimensão para a transparência empresarial: estudo de caso de quatro empresas brasileiras com atuação global. Revista de Administração Pública, v.40, n.6, p.10771096, 2006.

A CBPC - Companhia Brasileira de Produção Científica (CNPJ: 11.221.422/0001-03) detém os direitos materiais desta publicação. Os direitos referem-se à publicação do trabalho em qualquer parte do mundo, incluindo os direitos às renovações, expansões e disseminações da contribuição, bem como outros direitos subsidiários. Todos os trabalhos publicados eletronicamente poderão posteriormente ser publicados em coletâneas impressas sob coordenação da Sustenere Publishing, da Companhia Brasileira de Produção Científica e seus parceiros autorizados. Os (as) autores (as) preservam os direitos autorais, mas não têm permissão para a publicação da contribuição em outro meio, impresso ou digital, em português ou em tradução. 